\title{
JustificaÇÃo, Probabilidade E INDEPENDÊNCIA
}

\author{
JUSTIFICATION, PRoBABILITY, AND INDEPENDENCE
}

\author{
ANDRÉ NEIVA \\ PUCRS/CAPES, BRASIL \\ al.neiva@gmail.com \\ TATIANE MARKS \\ PUCRS, BRASIL \\ tatiane.marks@gmail.com
}

\begin{abstract}
Epistemic justification has been widely accepted as both a gradational and relational notion. Given those properties, a natural thought is to take degrees of epistemic justification to be probabilities. In this paper, we present a simple Bayesian framework for justification. In the first part, after putting the model in an evidentialist form, we distinguish different senses of "being evidence for" and "confirming". Next, we argue that this conception should accommodate the two relevant kinds of qualitative confirmation or evidential support. In the second part of the paper, we discuss the claim that this view is unable to satisfy the modified version of the conjunction closure for beliefs in probabilistically independent propositions. We defend that the underlying assumption on which this objection depends leads to an improper reading of the concept of epistemic probability. After providing a better interpretation of it, we put forward a rationale, which is based on the notion of conditional uncertainty, in support of a more plausible and restricted version of the closure of justification under conjunction.
\end{abstract}

Keywords: Justification $\bullet$ probability $\bullet$ conjunction closure $\bullet$ independence

\section{Introdução}

Diferente de conhecimento, epistemólogos geralmente pensam que justificação epistêmica é um fenômeno gradual. ${ }^{1}$ Avaliações comparativas entre graus de justificação motivam essa alegação. Um agente pode ter mais justificação na sua crença em $P$ do que na sua crença em $H$, assim como eventualmente pode ter o mesmo grau de justificação nas suas crenças em $P$ e $Q$. Da mesma forma, parece ser o caso que justificação é eminentemente relacional. Se a sua crença em $P$ é justificada, isso ocorre porque há algum justificador $R$ que confere status positivo a ela. Ou seja, a sua crença em $P$ é justificada por $R .^{2}$

Considerando tais propriedades formais, uma sugestão natural é explicar justificação pelos recursos da teoria da probabilidade. Neste artigo, exploramos uma tentativa nesse sentido, a concepção na qual o grau estritamente positivo de justificação 
de uma crença corresponde ao valor de uma função cujo argumento é uma probabilidade condicional. Após fornecer algumas definições e realizar distinções importantes, caracterizamos em mais detalhes no que consiste essa tese. Em seguida, mostramos que essa posição é mais forte se for compreendida em termos de suporte evidencial absoluto e incremental. Na segunda metade do artigo, discutimos um desafio que essa concepção enfrenta. O problema consiste na alegação de que uma função de probabilidade não é capaz de preservar o grau de justificação para conjunções entre proposições probabilisticamente independentes. A nossa sugestão é que o problema pode ser respondido pelo apelo a determinados resultados oferecidos pelo maquinário probabilístico, em particular pelo uso da noção de incerteza, e por uma melhor interpretação do conceito de probabilidade epistêmica.

\section{Justificação e Confirmação}

Ao longo dos anos, epistemólogos têm discordado significativamente acerca da natureza da justificação epistêmica e das condições que tornam uma crença justificada. ${ }^{3}$ A despeito de tal controvérsia, consideramos que as propriedades acima são em geral aceitas por epistemólogos: de que justificação é uma relação e deve ser concebida em termos graduais. Para usar uma terminologia de Peijnenburg e Atkinson (2014, p.202), a maioria das disputas diz respeito às propriedades materiais da justificação; se esta depende unicamente de condições internas a um agente ou é uma questão puramente externa, se é uma relação de emergência ou uma relação de transmissão, entre outras. Essas discordâncias, entretanto, não são sobre as suas propriedades formais ou lógicas. Neste trabalho, vamos nos concentrar nas propriedades formais da justificação.

A relação que nos interessa está expressa pelos seguintes enunciados:

(1) "X é justificado(a) por $J "$;

(2) "J justifica $X$ ".

Trata-se claramente de uma relação de dois lugares, já que conecta dois objetos ou entidades. De qualquer forma, dois pontos parecem ser pertinentes, nomeadamente, a natureza dos dois objetos $X$ e $J$ e o tipo de relação envolvida entre $X$ e $J$. Quanto à ontologia de $X$ e $J$, existem diferentes alternativas — por exemplo, se são eventos, proposições ou crenças —, sendo que tais objetos não precisam ser compostos pelo mesmo tipo de coisa. Para o presente propósito, é apropriado que $X$ seja uma crença de um agente $S$ e $J$ a evidência total disponível a $S$, sendo que esta será constituída somente de proposições; consequentemente, $X$ e $J$ serão constituídos por itens proposicionais. Dito de outro modo, o justificador $J$ corresponde ao corpo evidencial disponível a $S$ em um dado tempo, enquanto $X$ representa o objeto 
alvo da justificação. Uma vez que queremos investigar uma determinada concepção probabilística, "justificação" será entendida como uma relação de probabilização, a saber, como uma relação na qual o justificador torna o conteúdo da crença (uma proposição) provavelmente verdadeira. Caracterizaremos mais precisamente o sentido relevante de probabilidade abaixo. Esse será o tipo de relação lógica que importa para a discussão atual.

Três observações merecem atenção. Uma vez que $J$ é a evidência (proposicional) disponível ao agente, vamos conceber justificação em termos evidencialistas. Essa escolha pode causar alguma resistência por parte de um externista que pensa que $J$ poderia ser um evento, ao passo que haverá protesto de alguns internistas que aceitam que $J$ poderia ser um item não-proposicional tal qual uma experiência. Dessa maneira, alguém pode pensar que alguma forma de evidencialismo está sendo favorecida por essa escolha. Como dissemos, não examinaremos as condições materiais da justificação, afinal o foco é nas condições formais da justificação, e seria frutífero que o modelo pudesse ser usado por ambos os partidos, realizadas as alterações necessárias. Como Atkinson e Peijnenburg (2017, p.39) propõem, um modo de mitigar o desconforto é a ideia de que tais posições, internismo e externismo, são duas interpretações diferentes de um mesmo modelo formal (probabilístico) de justificação. ${ }^{4}$ Somos simpáticos a essa sugestão. A despeito da preferência por um formato evidencialista, o modelo utilizado aqui poderia ser reconstruído para posições externistas, em especial o confiabilismo. ${ }^{5}$ Seja como for, há uma razão, mesmo que pragmática, a favor da escolha acima. O modelo probabilístico a ser testado, cuja interpretação é epistêmica, usualmente toma proposições como os seus itens de entrada, não eventos ou outros tipos de objetos. É claro que há maneiras de descrever espaços de probabilidade em termos de eventos, mas isso nos levaria a outras questões e sob certo aspecto complicaria a nossa discussão. ${ }^{6}$

A segunda observação diz respeito à relação de justificação. Esta pode ser constituída por triplas da forma $\langle b, P, E\rangle$, sendo que $b$ é a crença de $S, P$ é proposição objeto de $b$ e $E$ é a sua evidência. Por economia, vamos adotar simplesmente o par $\langle P, E\rangle$. Por simplicidade, vamos nos deter apenas na atitude de crença. Eventualmente, atitudes doxásticas como a suspensão de juízo e a descrença, assumindo que elas também podem ser objetos de justificação, poderiam ser acomodadas. A terceira e última observação é a suposição mínima que fazemos em relação ao sentido de justificação epistêmica. Neste artigo, justificação é definida em termos de conducência ou orientação à verdade, como tipicamente é entendida na literatura em epistemologia. ${ }^{7}$ Nessa esteira, justificação está conectada com duas metas epistêmicas fundamentais: o acréscimo de verdades e a diminuição de falsidades no sistema de crenças de $S$. Voltaremos a esse ponto na seção 4.

Tornando essa relação mais precisa, assuma que $\mathscr{A}$ é uma álgebra Booleana finita de proposições e $\mathscr{E}$ é a evidência total disponível a $S$, enquanto $B$ forma o conjunto de 
proposições de $\mathscr{A}$ que $S$ crê ou, simplesmente, o conjunto de crenças de $S$. Quando $P \in B$, quer dizer que $S$ crê que $P$. Por sua vez, as crenças de $S$ e a sua evidência total são indexadas a um tempo $t$. Isso dá à justificação um sentido sincrônico. Em outras palavras, assumimos que justificação concerne a um dado tempo, ainda que seja perfeitamente possível que $S$ tenha menos (ou mais) justificação em $t$ do que em $t^{\prime}$. Como a relação é gradual, uma ideia simples é a de que uma função j mede o grau de justificação de $\langle P, E\rangle$, associando a esse par um número real. Assim, je é uma função que estabelece o quão justificada está a crença de $S$ de que $P$ é verdadeira, dada a sua evidência $E$. Formalmente, a função é representada da seguinte maneira:

$$
\mathfrak{j}: B \times \mathscr{E} \longmapsto \mathbb{R}
$$

Note que o conjunto $B \times \mathscr{E}$, o domínio de $\mathrm{j}$, inclui todos os pares $\langle P, E\rangle$. A princípio, $E$ poderia ser um subconjunto próprio de $\mathscr{E}$. No entanto, fixaremos $E$ como a totalidade de $\mathscr{E}$, o que implica que $E=\mathscr{E}$. Essa estratégia permite que a avaliação do grau de justificação seja sempre referente à evidência total disponível, não apenas relativamente a uma porção dela. Por motivos de simplificação, os valores assinalados por $\mathbf{j}$ serão determinados ou precisos, mas não excluímos a possibilidade de valores imprecisos ou vagos. ${ }^{8}$

Seremos tradicionais em relação ao maquinário de probabilidades, uma vez que aceitamos o cálculo de Kolmogorov (1956). Portanto, probabilidade categórica é a noção primitiva e probabilidades condicionais podem ser obtidas por um quociente desta última. Entretanto, vamos restringir o domínio das funções categórica e condicional ao conjunto $\mathscr{A}^{+}=\{P \in \mathscr{A}: 1>\operatorname{pr}(P)>0\}$, sendo que $\mathscr{A}^{+} \subset \mathscr{A}^{9}$ Isso faz com que probabilidades sejam regulares, considerando que $\mathscr{A}^{+}$é o conjunto de todas as proposições de $\mathscr{A}$ que têm probabilidades não extremas. ${ }^{10}$ Vale advertir, todavia, que essa restrição não impede que um corpo evidencial $E$ torne uma proposição $P$ maximamente provável. Ainda é possível que $\operatorname{pr}(P \mid E)=1$ : pense no caso em que $E$ implica $P$. Agora os conjuntos $\mathscr{E}$ e $B$ serão considerados subconjuntos distintos de $\mathscr{A}^{+}$. Em virtude disso, colocamos de lado a discussão acerca da justificação de tautologias, que sempre têm probabilidade máxima, e concedemos alguma plausibilidade inicial a qualquer elemento que pertença a $B$.

A interpretação relevante de probabilidade aqui é epistêmica ou evidencial, mas não desejamos associá-la a probabilidades subjetivas. Nessa perspectiva, probabilidades epistêmicas são sempre relativas à evidência total disponível e mensuram uma relação objetiva de suporte entre proposições, independentemente do grau de crença de um agente e do recurso a quocientes de apostas. Essa interpretação está mais próxima daquela defendida por Williamson (2000), em que não se requer uma análise do conceito de probabilidade epistêmica, do que daquela endossada por Maher (1996), onde probabilidade epistêmica diz respeito a uma função de crença gradual que todo 
agente racional deve adotar. Dito isso, agora clarificamos a relação de suporte evidencial que nos importa.

Existem diversos sentidos de suporte evidencial ou confirmação. De acordo com a distinção proposta por Carnap (1962, pp.21-3), amplamente aceita na comunidade (cf. Achinstein 2001; Crupi 2016), há três conceitos diferentes que podem ser expressos por "confirmar", "ser evidência para" e "suportar". São eles o qualitativo, o quantitativo e o comparativo. Os enunciados abaixo os exemplificam (respectivamente):

i. E confirma $P$;

ii. O grau de confirmação ou suporte que $E$ fornece a $P$ é $\zeta$;

iii. $E$ confirma mais fortemente $P$ do que $E^{*}$ confirma $P^{*}$.

Teorias probabilísticas fornecem uma explicação elegante e precisa de tais conceitos. Para o presente propósito, o que nos interessa é basicamente o primeiro deles. Há ainda duas maneiras nas quais se afirma que " $E$ confirma $P$ ", uma incremental e outra absoluta:

(3) E confirma incrementalmente $P$ sse $\operatorname{pr}(P \mid E)>\operatorname{pr}(P)$;

(4) $E$ confirma absolutamente $P$ sse $\operatorname{pr}(P \mid E)>\varepsilon$.

Observe que o modelo probabilístico padrão é numérico por natureza, mas isso não deve ser mal interpretado. Embora o cálculo de Kolmogorov assinale números reais a proposições, o sentido de confirmação em (3) e (4) é qualitativo, não quantitativo. Em (3) a relação relevante é ordinal, sem se comprometer exatamente em que grau $E$ suporta $P$, o que seria dado por uma teoria quantitativa da confirmação. Em (4) o acréscimo de um limiar de suficiência para confirmação absoluta é um sintoma de uma estimação qualitativa. Qualquer valor acima do limiar $\varepsilon$ significa status positivo no que se refere ao impacto confirmatório que um determinado corpo evidencial proporciona à proposição-alvo. Desde que acima do limiar, não importa qual deve ser exatamente o valor da função de probabilidade condicional para que haja confirmação em sentido absoluto. Quando acima de $\varepsilon, P$ tem probabilidade alta (condicional em $E$ ).

A seguir apresentamos a concepção segundo a qual justificação é definida em termos da noção em (4) e discutimos por que assumir a cláusula (3) fortalece essa visão. ${ }^{11}$

\section{Uma Teoria acerca do Grau de Justificação}

Uma sugestão atraente é a tentativa de explicar graus de justificação por meio de probabilidades condicionais. Isso equivale a algo como: 
(†) O grau de justificação da crença de $S$ em $P$, dada uma evidência $E$, corresponde a $f[p r(P \mid E)]$, dado que $f[p r(P \mid E)]>\varepsilon$.

Mais especificamente, $\mathfrak{j}$ é definida como:

$$
\mathfrak{j}(P, E)= \begin{cases}f[\operatorname{pr}(P \mid E)] & \text { se } f[\operatorname{pr}(P \mid E)]>\varepsilon, \\ 0 & \text { se } f[\operatorname{pr}(P \mid E)] \leq \varepsilon .\end{cases}
$$

Vale lembrar que é necessário esclarecer que tipo de função $f$ é. Tomaremos $f$ como uma função identidade. Se $f$ é uma função identidade, então $f(x)=x$. Portanto, trata-se de uma função que retorna o mesmo valor que é computado como o seu argumento, além de ser contínua. Como $f$ é uma função identidade cujo argumento é $\operatorname{pr}(P \mid E)$, os valores assinalados por $f$ se situam no intervalo unitário. Neste caso, $f$ é uma função estritamente crescente de $\operatorname{pr}(P \mid E)$. Significa que, para quaisquer $x, y \in I$ tal que $I \subset \mathbb{R}, f(x)>f(y)$ sempre que $x>y$. Intuitivamente, quer dizer que $f$ acompanha o crescimento de $\operatorname{pr}(P \mid E)$ monotonicamente. No entanto, observe que $\mathfrak{j}$ se caracteriza como uma função definida em trechos ou por partes. Quando o valor de $f$ estiver estritamente acima de $\varepsilon, \mathrm{j}(P, E)$ corresponderá ao valor da função de probabilidade condicional $\operatorname{pr}(P \mid E)$. Importa dizer que $\mathrm{j}$ não é idêntica a $f$, considerando que $\mathfrak{j}(P, E)=0$ se $f[\operatorname{pr}(P \mid E)] \in[0, \varepsilon]$. Ainda, $\mathfrak{j}$ não é contínua porque $\mathfrak{j}$ salta quando o seu valor supera $\varepsilon$. Quando $f[\operatorname{pr}(P \mid E)] \in(\varepsilon, 1]-v i z$. $(\varepsilon, 1]=\{x \in \mathbb{R}: 1 \geq x>\varepsilon\}-$, haverá justificação. Do contrário, quando menor ou igual ao limiar, não haverá justificação, deixando $j(P, E)=0$.

Trata-se de uma teoria probabilística do grau de justificação. De fato, essa caracterização de $j$ incorpora a condição (4) da seção anterior. Ou seja, porque o valor de $f$ precisa estar acima de um determinado limiar, a condição de confirmação absoluta deve ser satisfeita. Mais especificamente, o grau (positivo) de justificação da crença em $P$, considerando $E$, é equivalente à probabilidade posterior de $P$ dado $E$. Note, no entanto, que deve ser assinalado a $f[\operatorname{pr}(P \mid E)]$ um valor acima de algum limiar apropriado para justificação. Certamente pode haver alguma discussão sobre qual deve ser o valor exato de $\varepsilon$, se isso é fixado pelo contexto ou se $\varepsilon$ deve ser invariante ou rígido, sendo independente de condições contextuais. Seja como for, não entraremos em tal disputa. Contudo, pensamos que muitos estariam pelo menos dispostos a aceitar que $\varepsilon \in[.5,1$ ) (viz. $1>\varepsilon \geq .5$ ), eventualmente que $\varepsilon$ seja muito próximo de 1 .

Uma motivação para a imposição do limiar é a de que dificilmente diríamos que a crença em $P$ estaria justificada se o grau de probabilidade de $P$ condicional em $E$ fosse significativamente pequeno. Considere a proposta alternativa na qual o grau de justificação incorpora somente a condição de suporte incremental ou relevância probabilística. Um dos ônus de aceitar essa teoria mais fraca é o resultado de que a justificação será associada a graus realmente muito baixos, sem qualquer limiar 
específico de suficiência. Parece-nos que essa consequência não é epistemicamente desejável, visto que uma crença justificada está orientada à verdade e pensamos que um grau muito baixo corresponderia, pelo contrário, a uma orientação para a falsidade da crença-alvo. ${ }^{12}$ Apesar disso, mostraremos que é razoável incluir suporte incremental como uma condição necessária de $(\dagger)$.

De acordo com $(\dagger)$, suporte evidencial acima do limiar de suficiência $\varepsilon$ é suporte no nível de justificação. Significa que $E$ deve tornar $P$ altamente provável. Quanto maior for o grau de probabilidade de $P$ dada a evidência total, maior será o grau de justificação da crença em $P$. Como consequência de $\operatorname{pr}(P \mid E)>\varepsilon$, segue-se que $\operatorname{pr}(\neg P \mid E)<\varepsilon$. Mais precisamente, quando $\operatorname{pr}(P \mid E)>\varepsilon$ for o caso, $\operatorname{pr}(\neg P \mid E)<$ $1-\varepsilon$ também será o caso. ${ }^{13}$ Uma interpretação disso é oferecida pela alegação de que o risco da crença em $P$ ser falsa depende diretamente de quão provável é $\neg P$ dado $E$. Quanto menor for a probabilidade de $\neg P$ condicional em $E$, menor será o risco de $P$ ser falsa, levando em conta $E .{ }^{14}$ Como resultado, maior será o grau de justificação da crença em $P$. Assim como Adams (1998), entendemos que a incerteza (ou o risco) de $P$ é igual à probabilidade de $P$ ser falsa. Falaremos mais detalhadamente dessa noção na seção 4.

Como mencionamos, é suficiente que o limiar seja superado para que uma crença tenha justificação, tal como funciona para confirmação absoluta. Em outros termos, esse artifício dá uma dimensão qualitativa à justificação que caracterizamos em termos bem genéricos na seção anterior. Como consequência de $(\dagger)$, contudo, o grau de justificação vai variar em um determinado subintervalo $(\varepsilon, 1]$ (qualquer grau $\zeta$ de justificação é tal que $1 \geq \zeta>\varepsilon$ ), sendo que 1 é o valor máximo; isto é, 1 representa a melhor justificação que uma crença pode receber. Qualquer valor abaixo do limiar fará com que a crença na proposição-alvo não tenha justificação simpliciter, enquanto qualquer valor acima deixará essa crença justificada simpliciter. Fora a dimensão qualitativa, essa maneira de representar formalmente justificação confere sentido e precisão às expressões "mais justificado", "menos justificado" e "igualmente justificado" quando diferentes crenças de um ou mais agentes são avaliadas. Dito de outra forma, graus situados em $(\varepsilon, 1]$ fornecem diferentes níveis de justificação que crenças podem receber de um conjunto evidencial.

\subsection{Incrementando a Posição}

Antes de discutirmos algumas dificuldades que podem ser levantadas contra a teoria apresentada, há uma importante restrição a ser feita. Como destacamos anteriormente, a noção de suporte incremental é distinta da noção absoluta. Portanto, uma não implica a outra e, por esse motivo, podem vir separadas. Pode haver incremento da probabilidade de $P$ por $E$ sem que a probabilidade de $P$ condicional em $E$ ultra- 
passe o limiar para haver suporte absoluto. Simbolicamente equivale a:

$$
\operatorname{pr}(P \mid E)>\operatorname{pr}(P) \Longrightarrow \operatorname{pr}(P \mid E)>\varepsilon \text {. }
$$

Igualmente pode haver confirmação absoluta sem suporte evidencial incremental:

$$
\operatorname{pr}(P \mid E)>\varepsilon \Longrightarrow \operatorname{pr}(P \mid E)>\operatorname{pr}(P) .
$$

Para ver o primeiro tipo de situação, suponha que $\varepsilon=0.9$. Agora considere que $P$ é inicialmente tão plausível quanto $\neg P$, a saber, $\operatorname{pr}(P)=0.5$. Qualquer $\zeta$ onde $\varepsilon \geq \zeta>0.5$ tal que $\operatorname{pr}(P \mid E)=\zeta$ não fará com que $E$ torne $P$ altamente provável, embora seja o caso que $\operatorname{pr}(P \mid E)>\operatorname{pr}(P)$. Observe que $\zeta$ precisa ser estritamente maior que $\varepsilon$ para haver suporte absoluto, conforme fixamos acima. Normalmente há suporte absoluto sem incremental em situações onde $\operatorname{pr}(P)$ é alto e $\operatorname{pr}(E)>\operatorname{pr}(E \mid$ $P$ ). Dado que $\varepsilon=0.9$, assuma que, por exemplo, $\operatorname{pr}(E)=0.99>\operatorname{pr}(E \mid P)=0.98$ e que $\operatorname{pr}(P)=0.95$. Assim, $\operatorname{pr}(P \mid E) \approx 0.94$, tornando $\operatorname{pr}(P \mid E)>\varepsilon$. Acontece, no entanto, que $\operatorname{pr}(P)>\operatorname{pr}(P \mid E)$. Para que $\operatorname{pr}(P \mid E)>\operatorname{pr}(P)$ seja o caso, é necessário que $\frac{\operatorname{pr}(E \mid P)}{\operatorname{pr}(E)}>1$.

No contexto de discussão de (†), é possível que a crença de que $P$ alcance nível de justificação, ainda que $E$ não seja probabilisticamente relevante para $P$. Nesse sentido, $E$ poderia ser neutra evidencialmente ou poderia infirmar $P$ no nível incremental. Para expressar de outra maneira, haverá casos onde $E$ não é uma boa razão para crer que $P$ do ponto de vista incremental, mesmo embora o status da justificação da crença em $P$ seja positivo de acordo com $(\dagger)$. Em sentido rigoroso, pode ser o caso que $\operatorname{pr}(P \mid E) \in(\varepsilon, 1]$, o que corresponde ao fato de que $E$ justifica a crença em $P$, enquanto $\operatorname{pr}(P \mid E) \leq \operatorname{pr}(P)$.

Um exemplo, que é similar ao oferecido por Fitelson (2010, p.462), pode nos ajudar a ilustrar mais claramente tais circunstâncias. Suponha que uma rara doença $\alpha$ acometa cerca de $0.1 \%$ da população da região em que você vive. Supondo que $N$ representa “ $x$ não tem $\alpha$ ", significa que $\operatorname{pr}(N)=0.999$. Por seu turno, $\operatorname{pr}(\neg N)=0.001$. Assim, a probabilidade inicial de ter a doença é muito baixa. Em posse dessas informações, você decide realizar um exame de sangue que identifica $\alpha$. Ocorre, entretanto, que você sabe que o exame apresenta falsos positivos em torno de $1 \%$ das vezes. Por isso, $\operatorname{pr}(E \mid N)=0.01$, dado que $E$ é "o resultado do teste para $\alpha$ é positivo". Você também sabe que a confiabilidade do exame é bastante alta para pessoas que de fato possuem $\alpha$ : digamos que 99\%, ou seja, $\operatorname{pr}(E \mid \neg N)=0.99$. Admitindo que $\varepsilon=0.9$, $\operatorname{pr}(N \mid E) \approx 0.91>\varepsilon$, mas $\operatorname{pr}(N)=0.999>\operatorname{pr}(N \mid E)$. Portanto, mesmo que o resultado do teste seja positivo, você deveria acreditar que não tem a doença $\alpha$ do ponto de vista do suporte absoluto. Porém, na perspectiva incremental o resultado positivo não é razão para você acreditar que não tem a doença $\alpha$, pois $E$ diminui a probabilidade de $N$. 
Parece-nos que essa tensão causaria desconforto a muitos bayesianos. Como bem observa Fitelson (2010, p.462), grande parte dos bayesianos exige como condição necessária para $E$ ser evidência a favor da crença em $P$ que $E$ não infirme incrementalmente $P$. Na verdade, não seria nenhum exagero dizer que bayesianos estão dispostos a aceitar mais do que isso: não somente que $E$ não infirme $P$, mas igualmente que $E$ não seja neutra evidencialmente em relação a $P$. Com efeito, suporte incremental (ou relevância probabilística) tem sido a noção mais importante em teorias bayesianas do suporte evidencial, conceito sobre o qual há menos disputas. Além do mais, aceitando que o grau de justificação é dado por confirmação qualitativa, uma alegação natural é a de que esse grau não deve ser exclusivamente sensível ao suporte absoluto, mas que também deve incorporar a dimensão incremental. Essa parece ser a posição advogada por Fitelson.

Aqui cabe uma breve ressalva. Talvez seja correto afirmar que muitos bayesianos não queiram explicar justificação pelo recurso à teoria da confirmação, entendendo que os dois conceitos capturam fenômenos diferentes. Tendemos a nos incluir nesse grupo no que diz respeito à confirmação qualitativa, mas por ora guardamos alguns desafios e alternativas de resposta para a discussão a ser realizada na seção posterior. De todo modo, se isso fosse de alguma maneira defensável, também julgamos que a proposta deveria acomodar suporte incremental. O conflito seria suplantado caso fosse adicionada uma condição à concepção avançada em $(\dagger)$, segundo a qual $\operatorname{pr}(P \mid$ $E$ ) deve ser estritamente maior do que $\operatorname{pr}(P)$. Apesar de que ter crença justificada não se resume meramente a obter suporte evidencial incremental, este último deveria ser uma condição necessária imposta sobre $(\dagger)$.

Nesta altura, alguém pode resistir a essa manobra, alegando que a visão sobre o grau de justificação se tornaria muito forte. Voltando ao nosso exemplo, $E$ não justificaria a crença em $N$ se incluirmos a cláusula de suporte incremental. Esse resultado é de fato verdadeiro, mas a reformulação sugerida ainda pode encontrar refúgio nas seguintes considerações. Se $E$ infirma incrementalmente $P$, a probabilidade de $\neg P$ condicional em $E$ será maior do que a probabilidade inicial de $\neg P$. Para sermos mais precisos, a seguinte relação de mútua implicação é uma consequência da teoria da probabilidade:

$$
\operatorname{pr}(P \mid E)<\operatorname{pr}(P) \Longleftrightarrow \operatorname{pr}(\neg P)<\operatorname{pr}(\neg P \mid E) .{ }^{15}
$$

Ou seja, o risco de $P$ ser falsa será estritamente menor na ausência de $E$ do que ao tomar $E$ como verdadeira porque $E$ desempenha papel negativo em relação a $P$. Ao invés disso, $E$ exerce papel positivo sobre $\neg P$. Nessa perspectiva, seria surpreendente que $E$ justificasse a crença em $P$, uma vez que um dos sentidos importantes de "ser evidência para", talvez o principal deles, está apontando justamente para a direção oposta, a negação de $P$. Então, podemos nos perguntar: a concepção probabilística 
sobre o grau de justificação não deve englobar o melhor que uma evidência pode fornecer? Parece-nos que sim. O melhor que $E$ pode fazer é ser evidencialmente relevante e dar apoio suficiente para que a crença em $P$ tenha alta probabilidade. Ambos os sentidos de suporte evidencial devem ser satisfeitos. Em tais casos, $E$ será muito boa evidência a favor da crença em $P$. Embora isso torne crença justificada uma commodity mais difícil de se obter, o referido conflito desaparece. ${ }^{16}$

Uma reformulação é articulada nos seguintes termos:

( $\star$ O grau de justificação da crença de $S$ em $P$, dada uma evidência $E$, corresponde a $f[\operatorname{pr}(P \mid E)]$, dado que $f[\operatorname{pr}(P \mid E)]>\varepsilon$ e $\operatorname{pr}(P \mid E)>\operatorname{pr}(P)$.

Note que $\mathfrak{j}$ ainda segue a caracterização que apresentamos anteriormente, mas agora para que uma crença tenha status positivo de justificação os dois sentidos interessantes de confirmação qualitativa devem ser observados. A despeito de ser simples e intuitiva, alguns sérios problemas têm surgido contra essa concepção. No restante do artigo, discutimos um problema particularmente intrigante envolvendo independência probabilística. Mostraremos que, se empregarmos algumas ferramentas e definições do próprio aparato da teoria da probabilidade, $(\star$ ) é capaz de satisfazer uma versão de um importante princípio epistêmico, mas sem apelo à noção de independência.

\section{Fecho da Conjunção e Independência Probabilística}

Uma estratégia para refutar $(\star)$ seria mostrar que a função de probabilidade condicional não é capaz de satisfazer certos desideratos da justificação. Porque ( $\star$ ) não é sensível a tais desideratos, a sua descrição seria em última análise inapropriada. Tal linha de raciocínio é defendida por Shogenji $(2012$; 2018) e Atkinson e Peijnenburg (2017). ${ }^{17}$ Ao aceitarem uma aplicação restrita do princípio do fecho da justificação sob conjunção, tais autores pensam que o grau de justificação deve ser preservado para crenças em conjunções, o que não é satisfeito por uma função de probabilidade condicional.

O problema consiste basicamente no seguinte. Suponha um conjunto finito de proposições compatíveis $\mathscr{A}^{*}=\left\{P_{1}, \cdots, P_{n}\right\}$ tal que, dada a sua evidência total $E$, $S$ crê em cada uma delas com o mesmo grau de justificação $\zeta$. De acordo com $(\star)$, isso significa que, para cada $P_{i}, \operatorname{pr}\left(P_{i} \mid E\right)=\zeta$, onde $\zeta>\varepsilon$ e $\zeta>\operatorname{pr}\left(P_{i}\right)$. Uma vez que a crença em cada uma das proposições de $\mathscr{A}^{*}$ é justificada por $E$ em certo grau $\zeta$, alguém poderia razoavelmente esperar que $S$ tivesse justificação, o mesmo nível de justificação, para a crença na conjunção entre elas. Ocorre, todavia, que existem situações nas quais $\operatorname{pr}\left(P_{1} \wedge \cdots \wedge P_{n} \mid E\right)<\varepsilon$ é o caso, ao passo que $\operatorname{pr}\left(P_{i} \mid E\right)>\varepsilon$ se mantém para cada $P_{i}$. Em outras palavras, a função de probabilidade não preservará 
o grau exato de justificação das crenças de $S$ nos conjunctos para a crença de $S$ na conjunção. Isso tornará, por conseguinte, a crença de $S$ na conjunção injustificada, a despeito de haver justificação para as suas crenças individuais em cada membro de $\mathscr{A}^{*}$.

Há uma classe de casos na qual isso claramente acontece. Quando proposições são probabilisticamente independentes entre si, tanto incondicionalmente quanto condicionalmente em $E$, o grau de probabilidade da conjunção sofrerá diminuição. Vamos assumir que $\mathscr{A}^{*}$ é um tal conjunto de proposições independentes:

(*) Para quaisquer $P_{m}$ e $P_{k}$ de $\mathscr{A}^{*}(m \neq k), \operatorname{pr}\left(P_{m} \wedge P_{k}\right)=\operatorname{pr}\left(P_{m}\right) \times \operatorname{pr}\left(P_{k}\right) \mathrm{e}$ $\operatorname{pr}\left(P_{m} \wedge P_{k} \mid E\right)=\operatorname{pr}\left(P_{m} \mid E\right) \times \operatorname{pr}\left(P_{k} \mid E\right)$.

A título de exemplo, considere o caso mais simples onde $n=2 \mathrm{em} \mathscr{A}^{*}$. Ademais, assuma que, para cada $P_{i}, \operatorname{pr}\left(P_{i} \mid E\right)=0.94>\operatorname{pr}\left(P_{i}\right)$. Se $\varepsilon=0.9$, então $\operatorname{pr}\left(P_{i} \mid E\right)>\varepsilon$ para cada $P_{i}$, mas $\operatorname{pr}\left(P_{1} \wedge P_{2} \mid E\right) \approx 0.88<\varepsilon$. Haverá, portanto, diminuição do grau de probabilidade de tal maneira que deixará a crença na conjunção entre $P_{1}$ e $P_{2}$ abaixo do limiar de suficiência para justificação. Conforme $(\star), S$ estaria justificado em crer individualmente em cada $P_{i}$, mas não na sua conjunção. Em virtude desse resultado, os referidos autores julgam que a tese avançada em ( $\star$ ) não pode fornecer uma teoria apropriada sobre o grau de justificação. Para eles, admitindo que $S$ presumivelmente forma uma crença na conjunção-alvo, o mesmo grau de justificação deve ser preservado das crenças de $S$ em cada um dos conjunctos $P_{1}$ e $P_{2}$ para a sua crença na conjunção $P_{1} \wedge P_{2}$.

Algumas observações nos parecem pertinentes. Em primeiro lugar, devemos advertir que uma relação ordinal se mantém em geral entre a probabilidade da conjunção e a dos seus conjunctos. A probabilidade de uma conjunção nunca é maior do que a probabilidade de um dos seus conjunctos. Esse é um resultado elementar do cálculo de probabilidades que vale tanto para probabilidades categóricas como para probabilidades condicionais:

$$
\operatorname{pr}(P \wedge R) \leq \operatorname{pr}(P) \text { e } \operatorname{pr}(P \wedge R \mid E) \leq \operatorname{pr}(P \mid E) .{ }^{18}
$$

Em segundo lugar, o resultado do exemplo acima é generalizável para um conjunto (finito) mais extenso de proposições probabilisticamente independentes. Quanto maior for o número $n$ de proposições em $\mathscr{A}^{*}$, menor será o grau de probabilidade da conjunção entre essas proposições. Há uma circunstância, entretanto, em que o grau é sempre preservado. Para quaisquer $P_{k}$ e $P_{m}$ probabilisticamente independentes, quando $\operatorname{pr}\left(P_{k} \mid E\right)=1$ e $\operatorname{pr}\left(P_{m} \mid E\right)=1, \operatorname{pr}\left(P_{k} \wedge P_{m} \mid E\right)=1$ será o caso. ${ }^{19}$ Note que $(\star)$ não se compromete de nenhum modo com a exigência de atribuir grau máximo de justificação a todas as crenças justificadas de um agente. Diferentemente, a sua versão infalibilista faria essa reivindicação. Para um infalibilista da justificação, 
o nível de justificação de uma crença corresponde sempre ao nível máximo 1 . Neste caso, o grau seria trivialmente preservado. Embora não tenhamos explicitado antes, não vamos explorar essa versão forte acerca de $(\star)$. Ou seja, vamos mantê-la no formato enunciado no final da seção anterior, o que significa privilegiar uma teoria falibilista da justificação. Afinal, parece-nos que epistemólogos na sua vasta maioria estão inclinados a aceitar o falibilismo sobre a justificação.

Veja que Shogenji (2012, p.34) e Atkinson e Peijnenburg (2017, p.136) estão de fato adotando o princípio de que a justificação é fechada sob conjunções. Porém, há uma condição determinante. Não devemos considerar que o seu comprometimento é com uma aplicação ampla e irrestrita do princípio. Pelo contrário, eles aceitam uma versão estreita: o fecho da conjunção deve valer unicamente para crenças em proposições probabilisticamente independentes, seguindo a cláusula $(*)$. Seria basicamente o seguinte:

(FC) Dado que $P_{m}, P_{k} \in \mathscr{A}^{*}$, se a crença em $P_{m}$ e a crença em $P_{k}$ são justificadas por $E$, então a crença em $P_{m} \wedge P_{k}$ também é justificada por $E$.

A propósito, (FC) é um caso especial da máxima de acordo com a qual justificação é fechada sob implicação. Em sentido rigoroso, o fecho sob implicação (FI) equivale a: dado que $P_{1}, \cdots, P_{n} \in \mathscr{A}^{*}$, se as crenças em $P_{1}, \cdots, P_{n}$ são justificadas por $E$ e $\left\{P_{1}, \cdots, P_{n}, E\right\} \Longrightarrow R$, então a crença em $R$ também é justificada por $E$. Por limitação de espaço, vamos nos concentrar apenas em (FC) e suas variantes. É importante destacar que (FC) captura a intuição de que justificação simpliciter deve ser preservada, mas não é totalmente sensível à dimensão gradual da justificação. Dado que os seus diferentes níveis se situam no intervalo semi-aberto $(\varepsilon, 1]$, (FC) precisa ser ligeiramente modificada. A fim de capturar esse aspecto granular da justificação, Shogenji (2012, p.34) sugere o seguinte princípio, que ele denomina de o requisito geral da conjunção:

(GCR) Se $\mathrm{j}\left(P_{i}, E\right) \gtrless \varepsilon$ para cada $P_{i} \in \mathscr{A}^{*}$, então $\mathrm{j}\left(\bigwedge_{i=1}^{n} P_{i}, E\right) \gtrless \varepsilon$.

Por sua vez, um princípio ainda mais específico em relação ao grau de justificação é o que Shogenji rotula como o requisito especial da conjunção:

(SCR) Se $\mathrm{j}\left(P_{i}, E\right)=\zeta$ para cada $P_{i} \in \mathscr{A}^{*}$, então $\mathrm{j}\left(\bigwedge_{i=1}^{n} P_{i}, E\right)=\zeta$.

Como Shogenji (2012, p.34; 2018, p.84) demonstra, duas cláusulas são necessárias para que (SCR) seja implicado por (GCR). A primeira é a de independência expressa em $(*)$, enquanto a segunda concerne à natureza de $\mathrm{j}$ : para quaisquer $P \mathrm{e}$ $E, \mathfrak{j}(P, E)=g[\operatorname{pr}(P \mid E), \operatorname{pr}(P)]$, onde $g$ é uma função crescente de $\operatorname{pr}(P \mid E)$ e uma função decrescente de $\operatorname{pr}(P)$. Cabe enfatizar, no entanto, que essa maneira de definir $\mathbf{j}$ diverge fundamentalmente da visão estabelecida por $(\star)$, onde $\mathfrak{j}(P, E)=f[\operatorname{pr}(P \mid E)]$ 
quando $f[\operatorname{pr}(P \mid E)]>\varepsilon$ e dado que $\operatorname{pr}(P \mid E)>\operatorname{pr}(P)$. Por isso, vamos manter o restante da nossa discussão em termos de (GCR) e (SCR), porque ambos os princípios são mais específicos no que se refere ao aspecto granular e exato do grau de justificação, mas sem se comprometer com qualquer suposição de implicação.

Em linhas gerais, (SCR) materializa a alegação de que o nível de justificação deve permanecer igual no caso de (crenças em) conjunções entre proposições probabilisticamente independentes. Se todas elas individualmente têm o mesmo grau, esse grau deve ser conservado. Assim, a reivindicação não é simplesmente que deve haver justificação para crer na conjunção, porque o limiar de suficiência é superado, mas que o mesmo nível de justificação deve ser preservado. Se j for definida conforme a caracterização que oferecemos na seção anterior, acomodando os dois sentidos de suporte evidencial qualitativo, então (GCR) nem sempre será satisfeito e (SCR) será violado para qualquer $\zeta \in(\varepsilon, 1)($ viz. $1>\zeta>\varepsilon$ ), exceto quando $\zeta=1$.

A pergunta natural a se fazer agora diz respeito à motivação para que a justificação seja fechada sob conjunções em situações de independência probabilística. Mais precisamente, por que o grau de justificação deve permanecer igual nessa gama particular de casos? Como sinalizamos, esse parece ser justamente o ponto crucial da nossa discussão. Antes de discutirmos potenciais argumentos, gostaríamos de fazer uma pequena nota.

Diferentes versões do princípio do fecho da justificação têm sido objeto de discussão entre epistemólogos. Ao lado de consistência, normalmente se considera o requisito do fecho da justificação sob implicação como um candidato a restringir crenças de agentes racionais. Embora sejam intuitivamente atraentes, paradoxos como do prefácio (Makinson 1965) e da loteria (Kyburg 1961) tipicamente têm sido tomados como ameaças contundentes a esses princípios, provocando diversas reações e tentativas de resolução do problema. Em particular, o emprego indiscriminado do fecho da justificação sob conjunção nos revela a dificuldade, isto é, a sua aplicação reiterada leva o agente a manter um conjunto de crenças logicamente inconsistentes. ${ }^{20}$ De fato, existe uma variedade de posições e disputas na literatura envolvendo tais questões. ${ }^{21}$ Seja como for, no que tange ao fecho sob conjunção, há quem defenda a sua completa rejeição, incluindo Kyburg (1970) e Foley (2009), mas também existem aqueles que argumentam que princípios desse gênero são desideratos fundamentais da justificação, alegando que devem valer em geral ou para uma extensa gama de casos, entre eles estão Pollock (1983), Kaplan (1996) e Evnine (1999). As posições de Shogenji e Atkinson e Peijnenburg gravitam entre esses dois extremos, visto que exigem uma versão restrita do princípio. Não vamos levar adiante o debate acerca dos desafios impostos pelos paradoxos do prefácio e da loteria. Como mostraremos, a nossa tese é mais modesta. Em primeiro lugar, queremos desafiar a alegação de que o fecho sob conjunção restringe crenças probabilisticamente independentes e, em seguida, propomos uma alternativa teórica razoável ao defensor de $(\star)$. 
Em grande medida, a razão pela qual Atkinson e Peijnenburg (2017, p.136) defendem esse emprego restrito do fecho sob conjunção é oferecida em um exemplo. Aqui fornecemos uma situação um pouco diferente devido ao formato de $(\star)$. Essa alteração não causará nenhum prejuízo no que diz respeito à lição que eles tentam extrair. ${ }^{22}$ Imagine duas urnas com um total de 100 bolas cada. A primeira urna $U_{1}$ tem 82 bolas pretas e 18 bolas brancas, enquanto a segunda urna $U_{2}$ tem 82 bolas vermelhas e 18 bolas azuis. Além disso, 12 bolas são premiadas em $U_{1}$, onde 10 são brancas e 2 são pretas, ao passo que das 12 bolas premiadas em $U_{2} 10$ são de cor azul e 2 de cor vermelha. Suponha que $R$ é a proposição de que a bola sorteada em $U_{1}$ é branca, $A$ é a proposição de que a bola sorteada em $U_{2}$ é azul, $E$ é a proposição de que a bola sorteada é premiada e que o limiar $\varepsilon$ é 0.8 . Em posse de tais informações, a distribuição de probabilidade é tal que haverá suporte incremental e absoluto para $R$ e $A$ (cada uma condicional em $E$ ):

$$
\operatorname{pr}(R \mid E) \approx 0.833>\varepsilon>\operatorname{pr}(R) \text { e } \operatorname{pr}(A \mid E) \approx 0.833>\varepsilon>\operatorname{pr}(A) .
$$

Segundo ( $\star$ ), há justificação para crer que $R$, assim como para crer que $A$. Contudo, considerando que $R$ e $A$ são independentes probabilisticamente, não há justificação para crer na conjunção $R \wedge A$, levando em conta que $E$ é a evidência total. Como resultado, ambos (GCR) e (SCR) serão violados. Aplicando (*), segue-se que:

$$
\operatorname{pr}(R \wedge A)<\operatorname{pr}(R \wedge A \mid E) \approx 0.69<\varepsilon .
$$

Em casos dessa natureza, Atkinson e Peijnenburg (2017, pp.136-7) julgam que deveríamos esperar um veredito contrário ao de $(\star)$, ou seja, de que $E$ fornece o mesmo nível de justificação para acreditar em $R \wedge A$. Não compartilhamos a mesma intuição. Adicionalmente, não nos é claro que o exemplo constitui objeção à visão proposta por $(\star)$. Ainda pior, não vemos por que razão deveríamos pensar dessa maneira em virtude de que o exemplo não nos motiva a concluir que o princípio do fecho da conjunção deve restringir crenças em proposições probabilisticamente independentes; tampouco que o mesmo grau deve ser mantido. Está longe de ser inequívoco que o exemplo nos move em direção à sugestão que eles propõem, o que consistiria em razão a favor de (GCR) e (SCR). Salvo melhor juízo, não consideramos que o modelo acima constitui razão contra a posição de que o grau de justificação é explicado em termos de suporte absoluto e incremental.

Além do mais, alguém que rejeita completamente o fecho sob conjunção em primeiro lugar, portanto contra (GCR) e (SCR), também não veria problemas quanto à não-preservação do grau de justificação, salvaguardando $(\star)$. Porém, queremos apontar para um foco alternativo de resistência, um no qual retém uma aplicação do fecho. Uma resposta pode ser articulada com base na seguinte estratégia argumentativa. Embora a evidência total justifique as crenças individuais nos conjunctos, 
crer na conjunção envolve um risco maior de se obter uma falsidade. Quanto maior for o número de proposições envolvidas em uma conjunção, maior será o risco associado a ela. Uma função de probabilidade condicional é efetivamente sensível a esse risco e conjunções - principalmente quanto maior for a sua extensão (finita) - têm maior grau de risco em comparação ao risco de qualquer uma das proposições atômicas que as compõem. Nesse sentido, a defesa do proponente de $(\star)$ consistiria na alegação de que probabilidades condicionais capturam a intuição correta a respeito de crenças em proposições independentes.

Apesar de à primeira vista atraente, dois potenciais problemas acometem essa linha de raciocínio. Primeiro, admitindo independência, (GCR) (ou uma versão disso) pode ser satisfeito por ( $\star$ ), ainda que (SCR) não, para qualquer $\varepsilon<1$. Basta assumir que $n=2 \mathrm{em} \mathscr{A}^{*}$ e que, para cada $P_{i}, \operatorname{pr}\left(P_{i} \mid E\right)$ é grande o suficiente. Por exemplo, se $\operatorname{pr}\left(P_{i} \mid E\right)=0.98$ para ambos $P_{1}$ e $P_{2}$, então $\operatorname{pr}\left(P_{1} \wedge P_{2} \mid E\right) \approx 0.96$. Nessa circunstância, haveria justificação para crer que $P_{1} \wedge P_{2}$, desde que o limiar $\varepsilon$ seja estritamente menor do que 0.96 . A questão é que o proponente de $(\star)$ careceria de um argumento para legitimar que (GCR) se aplica a um determinado subconjunto de casos: notadamente quando a probabilidade de cada $P_{i}$ condicional em $E$ é alta. Se não fosse oferecida propriamente uma defesa da aplicação do princípio a tais condições particulares, então concederíamos que se trata de um resultado arbitrário para $(\star)$, o que obviamente se quer evitar.

Segundo, não obter falsidades é apenas um lado da moeda no que diz respeito aos dois objetivos epistêmicos da justificação, a saber, o incremento de crenças verdadeiras e a diminuição de crenças falsas no sistema doxástico de $S$. Para Shogenji (2012, pp.30-2; 2018, pp.79-80), uma função de probabilidade condicional é uma medida do risco envolvido em se obter falsidades, mas não acomoda o outro aspecto cognitivo relevante, que é o potencial relativo ao acréscimo de verdades. Como veremos a seguir, essa não é uma leitura caridosa do maquinário de probabilidades. A propósito, essa é a razão central pela qual Shogenji aceita o emprego limitado do fecho da conjunção, formulada nos princípios (GCR) e (SCR). Apesar de reconhecer que o risco em crer em uma conjunção é maior do que crer em qualquer um dos seus conjunctos, a sua alegação é que, no caso de crenças em proposições independentes, o mesmo nível de justificação deve ser preservado devido à ideia de que o risco é compensado pelo grande potencial que o agente tem em incluir verdades no seu sistema de crenças. Em outras palavras, se as crenças individuais em cada um dos conjunctos já se encontram justificadas, isso deveria permanecer no patamar da crença na conjunção por causa do potencial de aquisição de verdades. Por esse motivo, Shogenji julga que a não-preservação do grau de justificação é um resultado inconveniente.

Acreditamos que ambas as dificuldades são superadas com uma melhor interpretação da visão apresentada por $(\star)$. O resultado que mostraremos dispensa qualquer consideração ou suposição acerca da condição de independência probabilística e, 
presumivelmente, consegue acomodar as duas dimensões cognitivas da justificação.

Em teorias da lógica probabilística - por exemplo, Adams (1998) - a incerteza (ou o risco) de uma proposição é comumente definida como a probabilidade da sua negação: $u(P)=\operatorname{pr}(\neg P)=1-\operatorname{pr}(P) .^{23}$ Seguindo essa sugestão, podemos expandir a definição para a incerteza ou o risco condicional:

$$
u(P \mid E)=1-\operatorname{pr}(P \mid E) .
$$

Com essa noção e algumas poucas suposições, é possível demonstrar que, para quaisquer $P, Q$ e $E$, a soma da incerteza de $P$ condicional em $E$ e da incerteza de $Q$ condicional em $E$ é igual ou maior do que a incerteza de $P \wedge Q$ condicional em $E$ :

$$
[u(P \mid E)+u(Q \mid E)] \geq u(P \wedge Q \mid E) .^{24}
$$

Nessa perspectiva, o risco associado à conjunção será menor do que o somatório total do risco dos seus conjunctos, assumindo o mesmo corpo evidencial. Observe que, individualmente, o conjuncto continuará a possuir menor grau de risco do que uma conjunção:

$$
u(P \mid E) \leq u(P \wedge Q \mid E) .^{25}
$$

Agora, se $\varepsilon$ é o limiar, podemos estipular que $\Delta \varepsilon=(1-\varepsilon)$ é o anti-limiar. Enquanto o limiar é o indicador que demarca que a evidência total $E$ torna $P$ provavelmente verdadeira, o anti-limiar é exatamente o indicador na direção oposta, visto que demarca que $E$ torna $P$ provavelmente falsa. Quanto maior for $\operatorname{pr}(P \mid E)$, menor será $\operatorname{pr}(\neg P \mid E)$. Em sentido rigoroso, $\operatorname{pr}(P \mid E) \geq \varepsilon$ se e somente se $\operatorname{pr}(\neg P \mid E) \leq \Delta \varepsilon$. Por seu turno, se a quantidade total de incerteza em $[u(P \mid E)+u(Q \mid E)]$ estiver abaixo de $\Delta \varepsilon$, significa que $\operatorname{pr}(P \mid E)$ e $\operatorname{pr}(Q \mid E)$ terão valores altos, tornando $\operatorname{pr}(P \wedge Q \mid E)$ maior ou igual a $\varepsilon$ :

(^) Se $\Delta \varepsilon \geq[u(P \mid E)+u(Q \mid E)] \geq u(P \wedge Q \mid E)$, então $\operatorname{pr}(P \wedge Q \mid E) \geq \varepsilon$. $^{26}$

Vale notar que Sturgeon (2008, p.150) produz consequência semelhante para as noções de probabilidade e incerteza categórica, não para as suas variantes condicionais, mas admite uma interpretação subjetiva da função de probabilidade, distinta daquela que propusemos no início do artigo. Além disso, há algumas lições que são extraídas do resultado formal em (*). Como sugerimos, o limiar e o anti-limiar são parâmetros que definem qual é a orientação da proposição-alvo. Alegadamente, se $S$ acreditasse que $P$ com base em $E$ quando $\operatorname{pr}(P \mid E) \geq \varepsilon$, o potencial de inclusão de uma verdade no seu sistema de crenças seria grande. $O$ risco de inclusão de uma falsidade seria pequeno porque $\operatorname{pr}(\neg P \mid E) \leq \Delta \varepsilon$. Do contrário, se fosse o caso que se $S$ acreditasse que $P$ com base em $E$ quando $\operatorname{pr}(P \mid E) \leq \Delta \varepsilon$, o risco de inclusão de uma falsidade seria grande. $O$ ganho potencial de uma crença verdadeira seria 
pequeno porque $\operatorname{pr}(\neg P \mid E) \geq \varepsilon$. Naturalmente que, como evidência total disponível ao agente, $E$ é responsável sobre qual deve ser a orientação de $P$. Essa é uma das características do formato evidencialista de $(\star)$, onde uma função de probabilidade condicional, sob uma interpretação epistêmica, estabelece o quão forte $E$ probabiliza $P$. Em combinação com o que foi dito anteriormente, aqui está uma leitura mais favorável e apropriada do conceito de probabilidade epistêmica. Por isso, não nos parece justo atribuir a uma função de probabilidade epistêmica o papel limitado de determinar o risco de se obter falsidades.

Contudo, a conclusão que alcançamos, formalmente expressa ( $)$, não se resume a dizer que $\operatorname{pr}(P \mid E)$ e $\operatorname{pr}(Q \mid E)$ terão valores altos. Mostra, adicionalmente, que se a quantidade de incerteza envolvida for pequena o suficiente, isso tornará $\operatorname{pr}(P \wedge Q \mid E)$ maior do que o limiar. Quanto menor for a quantidade em $[u(P \mid E)+u(Q \mid E)]$, maior será o potencial de acréscimo de verdades. Quando $[u(P \mid E)+u(Q \mid E)] \leq$ $\Delta \varepsilon, E$ também tornará $P \wedge Q$ provavelmente verdadeira. Esse resultado tem uma consequência bastante clara, nomeadamente, haverá situações onde o princípio do fecho da conjunção será satisfeito. Mas, nesta altura, o defensor de que o grau de justificação é definido conforme $(\star)$ tem uma explicação plausível de por que esse princípio se aplica a uma gama muito específica de casos, escapando da acusação de arbitrariedade. Em casos em que a probabilidade condicional dos conjunctos é muito alta, tão alta que o seu somatório de incerteza é suficientemente baixo, $E$ fornecerá justificação para a crença em $P \wedge Q$. A justificação será transportada das crenças nos conjunctos para a crença na conjunção porque os conjunctos, dada a evidência total, provavelmente são verdadeiros e possuem grau baixo de incerteza.

De acordo com a nossa avaliação, o resultado formal disponível acima proporciona uma alternativa que evita a arbitrariedade que mencionamos, além de prescindir de qualquer suposição acerca de independência probabilística. Como enfatizamos, é difícil entender a motivação para aceitar a aplicação do princípio do fecho da justificação sob conjunção a crenças em proposições independentes. O exemplo de Atkinson e Peijnenburg é pouco elucidativo e convincente, ao passo que a apreciação de Shogenji não é legítima. Julgamos que ( $)$ nos apresenta um recurso explanatório bastante frutífero do maquinário probabilístico. Em particular, a interpretação que oferecemos de tal resultado, ao lado de uma leitura mais favorável do conceito de probabilidade epistêmica, auxilia o proponente de $(\star)$. Aos que consideram que o fecho da justificação sob conjunção possui um apelo intuitivo, eis uma explicação plausível de por que esse princípio se aplica à classe restrita de casos que apontamos anteriormente: quando a evidência total, no seu papel justificatório, probabiliza cada um dos conjunctos em um nível suficientemente alto, o status da justificação é mantido para a crença na conjunção. Isso ocorre justamente devido ao baixo grau de incerteza assinalado a cada um dos conjunctos. Em outras palavras, $E$ torna $P \wedge Q$ provavelmente verdadeira porque faz com que cada um desses conjunctos seja (in- 
dividualmente) muito provável. Por fim, cabe dizer que o modelo oferecido na seção 3 captura as duas propriedades mínimas que assumimos no início do artigo, que justificação é relacional e gradual. Trata-se de uma concepção simples, mas que torna a fala de graus de justificação, que epistemólogos comumente adotam, mais precisa.

Existem certas implicações importantes às quais precisamos nos ater neste momento. Devido ao resultado fornecido em ( $\bullet$ ), surge a necessidade de uma reforma na posição expressa em $(\star)$. O mais conveniente será incluir o limiar $\varepsilon$ como um grau suficiente para a justificação, ou seja, a mudança é de "estritamente maior que" para "maior que":

( $\star$ ) O grau de justificação da crença de $S$ em $P$, dada uma evidência $E$, corresponde a $f[\operatorname{pr}(P \mid E)]$, dado que $f[\operatorname{pr}(P \mid E)] \geq \varepsilon$ e $\operatorname{pr}(P \mid E)>\operatorname{pr}(P)$.

A definição de j passa a ser:

$$
j(P, E)= \begin{cases}f[\operatorname{pr}(P \mid E)] & \text { se } f[\operatorname{pr}(P \mid E)] \geq \varepsilon, \\ 0 & \text { se } f[\operatorname{pr}(P \mid E)]<\varepsilon .\end{cases}
$$

Em $(\star)$ o limiar $\varepsilon$ vai se situar no intervalo $(.5,1)(v i z .1>\varepsilon>.5)$, mas esta não é a única alteração. Como dissemos, o mesmo grau de justificação em geral não é conservado para a conjunção se o computarmos por meio de probabilidades. Tratase de uma propriedade do cálculo de probabilidades. No entanto, sinalizamos que, ao aceitar a estratégia desenvolvida, a justificação ainda poderá ser mantida para a conjunção. A versão modificada do princípio equivale a:

$\left(\mathrm{GCR}^{*}\right)$ Se $\mathrm{j}\left(P_{m}, E\right) \geq \varepsilon, \mathrm{j}\left(P_{k}, E\right) \geq \varepsilon$ e $\Delta \varepsilon \geq\left[u\left(P_{m} \mid E\right)+u\left(P_{k} \mid E\right)\right] \geq u\left(P_{m} \wedge P_{k} \mid E\right)$ para quaisquer $P_{m}, P_{k} \in \mathscr{A}^{+}(m \neq k)$, então $\mathrm{j}\left(P_{m} \wedge P_{k}, E\right) \geq \varepsilon .^{27}$

Embora o grau exato de justificação não seja preservado, (GCR*) impõe sob quais condições justificação simpliciter será mantida. Nesse contexto, o limiar $\varepsilon$ funciona como um parâmetro que confere um sentido qualitativo à justificação. Haverá justificação para a crença na conjunção desde que as cláusulas acima sejam satisfeitas, independentemente do valor preciso do intervalo $[\varepsilon, 1]$ que $f$ mapeia. Ou melhor, porque o limiar agora está incluído, o valor que $\mathrm{j}$ pode assumir estará no intervalo $[\varepsilon, 1]=\{x \in \mathbb{R}: 1 \geq x \geq \varepsilon\}$. Portanto, a dimensão qualitativa da justificação permanece intacta, como de fato acontece no caso do suporte evidencial absoluto, mas sem a forte demanda pela conservação do grau de justificação.

\section{Considerações Finais}

Ao longo do artigo, examinamos uma visão segundo a qual justificação epistêmica é explicada formalmente em termos probabilísticos. Argumentamos que a melhor 
versão dessa concepção é uma na qual ambas as condições de suporte evidencial qualitativo são satisfeitas, cuja melhor forma é fornecida por ( $\star$ ). Por um lado, alegamos que não há boa razão para pensar que o princípio do fecho sob conjunção deve ser aplicado exclusivamente a proposições probabilisticamente independentes. Por outro lado, o proponente de $(\star)$ encontra motivação para o emprego restrito do fecho da conjunção no próprio aparato formal da teoria da probabilidade e em uma leitura mais apropriada do conceito de probabilidade epistêmica. Talvez ao fim e ao cabo existam outras razões contra $(\star)$ que a destitua completamente. Seja como for, acreditamos que a estratégia apresentada no artigo pelo menos ameniza a força de um dos seus potenciais problemas. Em última análise, parece-nos que a tese apresentada em $(\star)$ dependerá em grande medida de quais são os outros desideratos e princípios que devem reger justificação epistêmica. Essa tarefa fica para uma investigação a ser desenvolvida em outra oportunidade.

\section{Apêndice}

Teorema 1: $u(P \mid E)+u(Q \mid E) \geq u(P \wedge Q \mid E)$.

Para quaisquer $P, Q$ e $E$, suponha que a incerteza de $P$ condicional em $E$ equivale a $u(P \mid E)=1-\operatorname{pr}(P \mid E)=\operatorname{pr}(\neg P \mid E)$ e a incerteza de $P \wedge Q$ condicional em $E$ equivale a $u(P \wedge Q \mid E)=1-\operatorname{pr}(P \wedge Q \mid E)=\operatorname{pr}(\neg(P \wedge Q) \mid E)$. Uma vez que $(P \wedge E) \equiv[(P \wedge E \wedge Q) \vee(P \wedge E \wedge \neg Q)]$, segue-se pelo cálculo de probabilidades que $\operatorname{pr}(P \wedge E)=\operatorname{pr}(P \wedge E \wedge Q)+\operatorname{pr}(P \wedge E \wedge \neg Q)$. Considerando que $(P \wedge E \wedge \neg Q) \Longrightarrow$ $(E \wedge \neg Q)$, segue-se cálculo de probabilidades que $\operatorname{pr}(E \wedge \neg Q) \geq \operatorname{pr}(P \wedge E \wedge \neg Q)$. Por substituição, $\operatorname{pr}(E \wedge \neg Q) \geq[\operatorname{pr}(P \wedge E)-\operatorname{pr}(P \wedge E \wedge Q)]$. Obtém-se $\operatorname{pr}(E \wedge \neg Q) \geq[\operatorname{pr}(P \mid$ $E) \times \operatorname{pr}(E)]-[\operatorname{pr}(P \wedge Q \mid E) \times \operatorname{pr}(E)]$, visto que $\operatorname{pr}(P \mid E)=\frac{\operatorname{pr}(P \wedge E)}{\operatorname{pr}(E)}$ e $\operatorname{pr}(P \wedge Q \mid E)=$ $\frac{\operatorname{pr}(P \wedge Q \wedge E)}{\operatorname{pr}(E)}$. Pela propriedade algébrica de que $(a \times b)-(a \times c)=a \times(b-c)$, segue-se que $\operatorname{pr}(E \wedge \neg Q) \geq \operatorname{pr}(E) \times[\operatorname{pr}(P \mid E)-\operatorname{pr}(P \wedge Q \mid E)]$. Manipulando um pouco os termos da fórmula, $\frac{\operatorname{pr}(E \wedge \neg Q)}{\operatorname{pr}(E)}=\operatorname{pr}(\neg Q \mid E) \geq[1-\operatorname{pr}(\neg P \mid E)]-[1-\operatorname{pr}(\neg(P \wedge Q) \mid E)]$. Portanto, segue-se que $\operatorname{pr}(\neg Q \mid E)+\operatorname{pr}(\neg P \mid E) \geq \operatorname{pr}(\neg(P \wedge Q) \mid E)$, que corresponde a $u(P \mid E)+u(Q \mid E) \geq u(P \wedge Q \mid E)$ se aplicarmos a definição de incerteza. QED.

Teorema 2 (^): Se $\Delta \varepsilon \geq[u(P \mid E)+u(Q \mid E)] \geq u(P \wedge Q \mid E)$, então $\operatorname{pr}(P \wedge Q \mid E) \geq \varepsilon$.

Além da definição de incerteza, suponha que o resultado do Teorema 1 é verdadeiro, a saber, $[u(P \mid E)+u(Q \mid E)] \geq u(P \wedge Q \mid E)$. Assuma que $\Delta \varepsilon=1-\varepsilon$. Adicionalmente, suponha que $\Delta \varepsilon \geq[u(P \mid E)+u(Q \mid E)]$. Por transitividade, obtém-se $\Delta \varepsilon \geq u(P \wedge$ $Q \mid E)$. Aplicando a definição de incerteza, segue-se que $\Delta \varepsilon \geq[1-\operatorname{pr}(P \wedge Q \mid E)]$. Manipulando um pouco os termos da fórmula anterior, conclui-se que $\operatorname{pr}(P \wedge Q \mid E) \geq$ $\varepsilon$. QED. 


\section{Referências}

Achinstein, P. 2001. The Book of Evidence. Cambridge: Cambridge University Press.

Adams, E. W. 1998. A Primer of Probability Logic. Stanford: CSLI Publications.

Alston, W. 2005. Beyond "Justification": Dimensions of Epistemic Evalution. Ithaca and London: Cornell University Press.

Atkinson, D.; Peijnenburg, J. 2017. Fading Foundations: Probability and the Regress Problem. Cham: Springer Open.

Carnap, R. 1962. Logical Foundations of Probability. 2nd ed. Chicago: The University of Chicago Press.

Christensen, D. 2004. Putting Logic in its Place: Formal Constraints on Rational Belief. New York: Oxford University Press.

Crupi, V. 2016. Confirmation. In: E. Zalta (ed.) The Stanford Encyclopedia of Philosophy. Winter 2016 Edition. https://plato.stanford.edu/archives/win2016/entries/confirmation/. Access: $15 / 01 / 2019$.

Evnine, S. J. 1999. Believing conjunctions. Synthese 118(2):201-27.

Feldman, R. 2003. Epistemology. Upper Saddle River: Prentice Hall.

Fitelson, B. 2010. Pollock on probability in epistemology. Philosophical Studies 148(3): 45565.

Foley, R. 2009. Beliefs, degrees of belief, and the lockean thesis. In: F. Huber; C. Schmidt-Petri (eds.) Degrees of Belief, pp.37-47. Dordrecht: Synthese Library.

Goldman, A. 2011. Toward a synthesis of reliabilism and evidentialism? In: T. Dougherty (ed.) Evidentialism and its Discontents pp.254-79. Oxford: Oxford University Press.

Hendricks, V. 2006. Mainstream and Formal Epistemology. Cambridge: Cambridge University Press.

Kaplan, M. 1996. Decision Theory as Philosophy. New York: Cambridge University Press.

Kolmogorov, A. N. 1956. Foundations of the Theory of Probability. 2nd ed. New York: Chelsea Publishing Company.

Kyburg, H. E. 1961. Probability and the Logic of Rational Belief. Middletown: Wesleyan University Press.

- 1970. Conjunctivitis. In: M. Swain (ed.) Induction, Acceptance, and Rational Belief, pp.55-82. Dordrecht: Reidel.

Liu, B. 2007. Uncertainty Theory. 2nd ed. Berlin: Springer-Verlag.

Maher, P. 1996. Subjective and objective confirmation. Philosophy of Science 63(2): 149-74.

Makinson, D. 1965. The paradox of the preface. Analysis 25(6): 205-7.

Moser, P. 1989. Knowledge and Evidence. Cambridge: Cambridge University Press.

Nozick, R. 1981. Philosophical Explanations. Cambridge: Harvard University Press.

Peijnenburg, J.; Atkinson, D. 2014. The need for justification. Metaphilosophy 45(2): 201-10.

Pollock, J. L. 1983. Epistemology and probability. Synthese 55(2): 231-52.

Shogenji, T. 2012. The degree of epistemic justification and the conjunction fallacy. Synthese 184(1): 29-48.

- 2018. Formal Epistemology and Cartesian Skepticism. New York: Routledge.

Smith, M. 2010. What else justification could be? Noûs 44(1): 10-31.

. 2018. The logic of epistemic justification. Synthese 195(9): 3857-75.

Sosa, E. 1999. How to defeat opposition to Moore. Philosophical Perspectives 13(1): 141-53. 
Sturgeon, S. 2008. Reason and the grain of belief. Noûs 42(1): 139-65.

Swinburne, R. 2001. Epistemic Justification. Oxford: Clarendon Press.

Turri, J.; Klein, P. 2014. Ad Infinitum: New Essays on Epistemological Infinitism. Oxford: Oxford University Press.

Williamson, T. 2000. Knowledge and its Limits. Oxford: Oxford University Press.

\section{Notas}

${ }^{1}$ Trata-se de uma sugestão bastante difundida entre epistemólogos. De qualquer maneira, a título de exemplo, ver Swinburne (2001, p.11), Feldman (2003, p.21) e Turri e Klein (2014, p.5).

${ }^{2}$ Tais aspectos formais da justificação também são enfatizados por Peijnenburg e Atkinson (2014). Combinando ambas as propriedades, é igualmente possível que o grau de justificação da crença em $P$ seja maior quando baseada em $R$ do que quando baseada em $R^{\prime}$ e que o grau de justificação da crença em $P$ baseada em $R$ seja maior do que o grau de justificação da crença em $Q$ baseada em $R$.

${ }^{3} \mathrm{~A}$ maioria dos epistemólogos concordam que justificação mais crença verdadeira não é suficiente para o conhecimento. Entretanto, muitos ainda julgam que a noção de justificação é um dos ingredientes necessários para posse de tal status; notáveis exceções são Nozick (1981) e Sosa (1999), por exemplo. Não raramente justificação é pensada como uma boa indicação de que uma crença é verdadeira ou aquilo que torna uma crença verdadeira uma candidata genuína ao status de conhecimento. Como falaremos a seguir, esse é o sentido que assumiremos ao longo do artigo. Todavia, não vamos discutir como o modelo apresentado se conecta mais intimamente com conhecimento, embora tal questão esteja no horizonte de futuras considerações. A respeito dos vários sentidos de justificação na literatura, ver Alston (2005).

${ }^{4} \mathrm{~A}$ neutralidade do maquinário de probabilidades que Atkinson e Peijnenburg apontam está contida na seguinte passagem (tradução nossa): "Afinal de contas, internistas, externistas, evidencialistas e confiabilistas não diferem em relação ao cálculo de probabilidades (...). As únicas diferenças entre eles são sobre interpretações: enquanto os internistas interpretam $X$ e $J$ de uma maneira interna, os externistas os interpretam de um ponto de vista externo, e ao passo que os evidencialistas explicam a relação de probabilidade em termos lógicos, os confiabilistas a explicam em termos nomológicos, tipicamente em termos de causalidade probabilística. Contudo, essas são apenas diferenças nas interpretações e elas não tocam no nível formal subjacente (2017, p.39)". Substituímos as variáveis $A_{i}$ e $A_{j}$ empregadas pelos referidos autores por $X$ e $J$ para melhor se encaixar com o nosso contexto de discussão.

${ }^{5}$ Cabe notar que ultimamente tem havido reações na literatura que tentam aproximar, por exemplo, o evidencialismo do confiabilismo. Alston (2005) defende que as duas posições são praticamente idênticas. O próprio Goldman (2011) tem se empenhado em estabelecer essa aproximação.

${ }^{6}$ Ainda que filósofos majoritariamente optem por sentenças ou proposições como os objetos de uma função de probabilidade, essa questão depende fundamentalmente do tipo de interpretação de probabilidade que se está assumindo. Quando a probabilidade relevante é epistêmica, é natural adotar proposições em vez de eventos como os objetos do domínio de 
uma função probabilística. Se estamos modelando probabilidades objetivas ou físicas, parece fazer mais sentido que os objetos sejam eventos.

${ }^{7}$ A título de exemplo, ver Moser (1989, pp.42-3), Swinburne (2001, p.1) e Hendricks (2006, p.6).

${ }^{8}$ Diferente de um grau preciso, um grau impreciso de justificação corresponde a um subintervalo $[a, b] \subseteq[c, d]$, sendo que $[c, d]$ é a imagem da função j. No momento, não precisamos nos preocupar com isso.

${ }^{9}$ Mais precisamente, ao passo que a função categórica é de um lugar, a função de probabilidade condicional é de dois lugares, nomeadamente, $\operatorname{pr}(\bullet): \mathscr{A}^{+} \longmapsto[0,1]$ e $\operatorname{pr}(\bullet \mid \bullet)$ : $\mathscr{A}^{+} \times \mathscr{E} \longmapsto[0,1]$. Na verdade, o domínio da função condicional é o conjunto $\mathscr{A}^{+} \times \mathscr{E}$, lembrando que $\operatorname{pr}(X \mid Y)=\frac{\operatorname{pr}(X \wedge Y)}{\operatorname{pr}(Y)}$. Significa que a função categórica mapeia as proposições de $\mathscr{A}^{+}$para o intervalo unitário e a função de probabilidade condicional mapeia todos os pares da forma $\langle P, E\rangle$ para o intervalo unitário.

${ }^{10}$ Regularidade exige que probabilidade 0 seja assinalada somente a contradições e probabilidade 1 somente a tautologias. O conjunto $\mathscr{A}^{+}$exclui verdades e falsidades lógicas de $\mathscr{A}$.

${ }^{11}$ Uma sugestão seria investigar se o grau de justificação pode ser dado por confirmação quantitativa, expresso pelo conceito que aparece em ii. Shogenji $(2012 ; 2018)$ persegue esse caminho, defendendo que o grau de justificação deve ser dado por uma medida de confirmação quantitativa. Embora interessante, não avaliaremos a sua proposta agora. Na seção 4, todavia, discutimos a sua objeção à proposta exposta na seção 3 , que é a sua principal motivação para endossar uma teoria alternativa.

${ }^{12}$ Além disso, há considerações sobre conhecimento que poderiam ser trazidas à tona. Afinal, graus baixos não parecem constituir nível suficiente para conhecimento. Se justificação realmente é gradual, parece razoável esperar que a crença-alvo atinja um nível alto de justificação para que seja uma legítima candidata a constituir conhecimento; talvez com a exigência alta de que 1 é o nível do conhecimento.

${ }^{13}$ Assuma que $\operatorname{pr}(P \mid E)>\varepsilon$. Pelo cálculo de probabilidades, $\operatorname{pr}(P \mid E)=1-\operatorname{pr}(\neg P \mid E)$. Por substituição, $1-\operatorname{pr}(\neg P \mid E)>\varepsilon$. Por álgebra simples, $\operatorname{pr}(\neg P \mid E)<1-\varepsilon$.

${ }^{14}$ Por essa razão, a tese avançada em $(\dagger)$ é o que Martin Smith $(2010 ; 2018)$ chama de 'minimização do risco'. Autores como Shogenji (2018) consideram que ( $\dagger$ ) tem um formato Lockeano. Geralmente a tese Lockeana da crença conecta graus probabilísticos de crença e crença racional. Aqui, diferentemente, nos interessa a relação entre probabilidade epistêmica, não probabilidade subjetiva, e justificação.

${ }^{15}$ Suponha que $\operatorname{pr}(P)>\operatorname{pr}(P \mid E)$. Pelo cálculo de probabilidades, $1-\operatorname{pr}(\neg P)>1-\operatorname{pr}(\neg P \mid$ $E)$, que é o mesmo que $\operatorname{pr}(\neg P \mid E)>\operatorname{pr}(\neg P)$. Segue-se que $\operatorname{pr}(P)>\operatorname{pr}(P \mid E) \Longrightarrow \operatorname{pr}(\neg P \mid$ $E)>\operatorname{pr}(\neg P)$. Agora assuma que $\operatorname{pr}(\neg P \mid E)>\operatorname{pr}(\neg P)$. Pelo cálculo de probabilidades, $1-\operatorname{pr}(P \mid E)>1-\operatorname{pr}(P)$. Por álgebra simples, concluímos que $\operatorname{pr}(P)>\operatorname{pr}(P \mid E)$. Dessa maneira, $\operatorname{pr}(\neg P \mid E)>\operatorname{pr}(\neg P) \Longrightarrow \operatorname{pr}(P)>\operatorname{pr}(P \mid E)$. Assim, conseguimos o resultado acima.

${ }^{16}$ Mais uma vez há considerações sobre conhecimento que poderíamos fazer. Dificilmente diríamos que a crença em $P$ é uma boa candidata a constituir conhecimento se em algum sentido importante $E$ não é evidência para a crença em $P$. Se justificação em nível de conhecimento é a preocupação primária, parece razoável esperar que a evidência total não deponha contra a crença-alvo. 
${ }^{17}$ Martin Smith (2018) também adota essa via contra $(\star)$, mas avalia um grupo mais amplo de princípios aos quais justificação epistêmica deve obedecer. Não vamos discutir aqui os princípios oferecidos por Smith, se afinal são ou não desideratos da justificação. Muito embora o projeto de encontrar os principais desideratos da justificação nos pareça interessante e digno de se perseguir, isso nos levaria a um debate mais extenso e intrincado do que a nossa tarefa atual se propõe a investigar.

${ }^{18}$ Pelo cálculo de probabilidades, $\operatorname{pr}(P)=\operatorname{pr}(P \wedge R)+\operatorname{pr}(P \wedge \neg R)$. Se $\operatorname{pr}(P \wedge \neg R)=0$, então $\operatorname{pr}(P)=\operatorname{pr}(P \wedge R)$. Se $\operatorname{pr}(P \wedge \neg R)>0$, então $\operatorname{pr}(P)>\operatorname{pr}(P \wedge R)$. Portanto, $\operatorname{pr}(P \wedge R) \leq \operatorname{pr}(P)$. Pelo mesmo raciocínio, $\operatorname{pr}(P \wedge E) \geq \operatorname{pr}(P \wedge E \wedge R)$. Pelo uso da noção de probabilidade condicional, $\operatorname{pr}(P \mid E) \times \operatorname{pr}(E) \geq \operatorname{pr}(P \wedge R \mid E) \times \operatorname{pr}(E)$. Portanto, $\operatorname{pr}(P \mid E) \geq \operatorname{pr}(P \wedge R \mid E)$.

${ }^{19} \mathrm{Na}$ realidade, esse resultado pode ser obtido sem a suposição de independência. Desde que $P_{k}, P_{m}$ e $E$ sejam compatíveis entre si, $\operatorname{pr}\left(P_{k} \wedge P_{m} \mid E\right)=1$ porque $\operatorname{pr}\left(P_{k} \wedge P_{m} \mid E\right)=\operatorname{pr}\left(P_{k} \mid\right.$ $\left.P_{m} \wedge E\right) \times \operatorname{pr}\left(P_{m} \mid E\right)$. Se aceitarmos a propriedade de monotonicidade, $\operatorname{pr}\left(P_{k} \mid P_{m} \wedge E\right)=1$, já que $\operatorname{pr}\left(P_{k} \mid E\right)=1$. O problema é que esse tipo de monotonicidade infringe a máxima segundo a qual justificação é anulável por evidência adicional. Para outras versões de monotonicidade, ver Smith (2018).

${ }^{20}$ Imagine uma loteria justa e extensa tal que um agente $S$ possui um bilhete. É natural assumir que $S$ está justificado em crer que o seu bilhete é um dos perdedores, já que é improvável que ele seja o vencedor. Acontece que, para cada bilhete $i$ da loteria, é improvável que $i$ vença. Assim, $S$ estaria justificado em crer que cada um dos bilhetes perderá. Admitindo que a justificação é fechada sob conjunções, $S$ está justificado em crer que nenhum bilhete é o vencedor e que algum é o vencedor, uma vez que ele sabe que a loteria é justa. Seguindo Atkinson e Peijnenburg (2017, p.136), estamos inclinados a pensar que casos de loteria justa são de dependência negativa. Para quaisquer bilhetes de loteria $m$ e $k(m \neq k)$ tal que $b_{i}$ é "o bilhete $i$ é o vencedor", $\operatorname{pr}\left(\neg b_{m} \mid \neg b_{k}\right)<\operatorname{pr}\left(\neg b_{m}\right)$, a saber, a probabilidade do bilhete de número $m$ perder é maior do que a probabilidade do bilhete de número $m$ perder condicional no fato de que o bilhete de número $k$ perdeu. Isso pode ser estendido para um número (finito) maior de bilhetes perdedores. Para eles, o problema é neutralizado porque o requisito do fecho sob conjunção não se aplica a tais casos. Para nós, nem mesmo a condição de suporte incremental parece ser satisfeita, considerando que a relação relevante é de dependência negativa. Apesar disso, não parece óbvio que tal propriedade se aplica igualmente a casos de prefácio, pelo menos não em geral, já que as relações entre as alegações feitas no corpo do livro parecem ser complexas. A suposição de que algumas alegações contidas no corpo do livro suportam outras é bastante razoável. Portanto, haveria uma relação de dependência positiva em um subconjunto de alegações feitas no corpo do livro. Da mesma forma, também haveria uma relação de independência em outro subconjunto de alegações.

${ }^{21}$ Para uma visão geral bastante informativa dessa discussão, ver Christensen (2004), em especial os capítulos 3 e 4. Deve-se ressaltar que Christensen coloca o debate em termos da racionalidade da crença, mas sem assumir a tese de que justificação e crença racional são equivalentes.

${ }^{22} \mathrm{O}$ seu exemplo original envolve somente suporte evidencial incremental. Este, segundo eles, deve ser uma condição necessária da justificação, mas sem que esta incorpore alto grau de probabilidade. Para mais detalhes, ver Atkinson e Peijnenburg (2017), especialmente os capítulos 3 e 6 .

${ }^{23}$ Ainda que Sturgeon (2008) prefira "risco" à "incerteza", temos usado tais termos inter- 
cambiavelmente e manteremos essa prática. Aproveitamos para fazer uma pequena advertência ao leitor. A noção de incerteza aqui não deve ser confundida com aquela que é definida na teoria matemática da incerteza, geralmente entendida como uma rival da teoria da probabilidade. Para mais informações, ver Liu (2007).

${ }^{24}$ Esse resultado é equivalente a $[1-\operatorname{pr}(P \mid E)]+[1-\operatorname{pr}(Q \mid E)] \geq[1-\operatorname{pr}(P \wedge Q \mid E)]$. A sua demonstração está disponível no apêndice a este artigo (teorema 1). O leitor interessado pode encontrar a demonstração no caso de incerteza categórica em Adams (1998, pp.32-3). Por indução matemática, ambos os resultados (categórico e condicional) são generalizáveis. Deixamos esse encargo ao leitor.

${ }^{25}$ Posto que $\operatorname{pr}(P \mid E) \geq \operatorname{pr}(P \wedge Q \mid E)$, segue-se que $1-\operatorname{pr}(\neg P \mid E) \geq 1-\operatorname{pr}(\neg(P \wedge Q) \mid E)$. Assim, $\operatorname{pr}(\neg P \mid E) \leq \operatorname{pr}(\neg(P \wedge Q) \mid E)$. Por substituição, conclui-se que $u(P \mid E) \leq u(P \wedge Q \mid E)$.

${ }^{26}$ A demonstração de $(\bullet)$ está disponível no apêndice a este artigo (teorema 2 ).

${ }^{27}$ Lembre-se que o conjunto relevante agora é $\mathscr{A}^{+}=\{P \in \mathscr{A}: 1>\operatorname{pr}(P)>0\}$, já que dispensamos a cláusula de independência probabilística. A versão generalizada de (GCR $\left.{ }^{*}\right)$ seria: se $\mathrm{j}\left(P_{i}, E\right) \geq \varepsilon$ e $\Delta \varepsilon \geq \sum_{i=1}^{n}\left[u\left(P_{i} \mid E\right)\right] \geq u\left(\bigwedge_{i=1}^{n} P_{i} \mid E\right)$ para qualquer $P_{i} \in \mathscr{A}^{+}$, então $\mathrm{j}\left(\bigwedge_{i=1}^{n} P_{i}, E\right) \geq \varepsilon$, o que incluiria a forma generalizada de $(\bullet)$.

\section{Agradecimentos}

Gostaríamos de agradecer aos professores e colegas dos seminários "Conhecimento \& Linguagem" e "Epistemologia Analítica", ambos realizados no primeiro semestre de 2018 no Departamento de Filosofia da PUCRS, pelos comentários e críticas a versões preliminares do presente artigo: Cláudio Almeida, Rodrigo Borges, Kátia Etcheverry, Rogel de Oliveira, Felipe Medeiros, João Fett, Gregory Gaboardi, Samuel Cibils, Eduardo Alves e Paulo Caliendo. Também somos gratos a Luis Rosa e Danilo Dantas pelas sugestões e comentários detalhados aos resultados mais técnicos fornecidos e examinados ao longo do texto. Estamos igualmente em débito com dois pareceristas anônimos pelas observações e críticas a diversas passagens do texto. Todas as sugestões oferecidas nos permitiram aperfeiçoar e dar maior clareza ao conteúdo do artigo. Por fim, importa dizer que este estudo foi parcialmente financiado pela Coordenação de Aperfeiçoamento de Pessoal de Nível Superior - Brasil (CAPES) — Código de Financiamento 001. 